\title{
Article \\ The Effect of Class C Fly Ash on the Plasticity and Ageing of Ceramic Mixtures Based on Kaolin
}

\author{
Radomir Sokolar*(D) and Martin Nguyen (D)
}

Citation: Sokolar, R.; Nguyen, M. The Effect of Class C Fly Ash on the Plasticity and Ageing of Ceramic Mixtures Based on Kaolin. Materials 2021, 14, 2761. https://doi.org/ $10.3390 / \mathrm{ma} 14112761$

Academic Editor: Dario De Domenico

Received: 12 April 2021

Accepted: 20 May 2021

Published: 23 May 2021

Publisher's Note: MDPI stays neutral with regard to jurisdictional claims in published maps and institutional affiliations.

Copyright: (c) 2021 by the authors. Licensee MDPI, Basel, Switzerland. This article is an open access article distributed under the terms and conditions of the Creative Commons Attribution (CC BY) license (https:// creativecommons.org/licenses/by/ $4.0 /)$.
Faculty of Civil Engineering, Institute of Technology of Building Materials and Components, Brno University of Technology, Veveri 331/95, 60200 Brno, Czech Republic; nguyen.m@fce.vutbr.cz

* Correspondence: sokolar.r@fce.vutbr.cz; Tel.: +420-54114-7501

\begin{abstract}
The main aim of the presented article is to describe the behavior of class C fly ash-kaolin plastic doughs during the ageing process. Class C fly ash (CCFA) from the fluidized technology of fuel combustion in a thermal power plant was used as a non-plastic admixture to modify the plasticity in a kaolin-quartz sand mixture (for example, the base of a porcelain mixture). The ageing of plastic ceramic dough determined the effect of the CCFA admixture (0-10-20 wt. \%) on the initial water content, plasticity (according to the Pfefferkorn test) and bulk density of a dried green body. The main feature of the CCFA admixture in the kaolin-quartz sand mixture is a solidifying effect. Fly ash increases the initial (mixing) water for the preparation of ceramic dough with constant plasticity (30 mm height of deformed cone Hf, according to the Pfefferkorn test), and Hf increases as the dough ages (the dough solidifies faster and loses its plasticity) with the addition of class $C$ fly ash. The effect of CCFA addition on the plasticity and ageing of kaolin-quartz sand dough is documented on Bigot curves: higher content of fly ash decreases the drying shrinkage of the plastic dough, especially when drying samples that have been aged for $24 \mathrm{~h}$ in a plastic wrap (without the possibility of drying). The plastic dough's ageing increases the porosity of the dried green body with increased content of CCFA in the raw materials mixture and increased ageing time.
\end{abstract}

Keywords: class C fly ash; plasticity; dough; ageing; bulk density

\section{Introduction}

Fluidized fly ash, class C fly ash (CCFA) according to ASTM C618-12a, is an energetic byproduct derived from the combustion of a coal-limestone (dolomite) mixture in fluidized bed boilers in thermal power plants at lower temperatures (about $800^{\circ} \mathrm{C}$ ). This is different from the traditional combustion of pure solid fuel (coal) at about $1400{ }^{\circ} \mathrm{C}$, where classical high-temperature fly ash (CFA) is produced. The Czech Republic produces 14 million tons of energetic byproducts annually and 1.5 million tons $(\approx 15 \%)$ of CCFA.

There are no publications on the effect of CCFA on the plasticity and ageing of ceramic dough. Only several studies in the geotechnical area exist, which generally study the interaction between soils and different kinds of fly ashes. Class $\mathrm{C}$ fly ash with a high content of $\mathrm{CaO}$ (41\%, according to the chemical analysis) for the stabilization of expansive soil was investigated, and various geotechnical properties of different ratios of clay:fly ash (up to $40 \%$ ) are presented [1]. Similar results are presented in [2], showing that the liquid limit value, plastic limit value and plasticity index decreased with increasing fly ash content (without specification, $13.5 \%$ of $\mathrm{CaO}$, according to the chemical composition, indicating that it should be CCFA). Class $\mathrm{C}$ fly ash, lime and Portland cement were used as traditional stabilizers for lean clay soil [3], and the geotechnical properties are presented as follows: both types of fly ashes (classes $\mathrm{C}$ and F) can be recommended as effective stabilizing agents for the improvement of soil stabilization. Class $\mathrm{C}$ fly ash has a stronger/greater pozzolanic effect compared to Class F fly ash in soil stabilization [4]. Class F fly ash $(1.13 \%$ of $\mathrm{CaO})$ suppressed swelling, decreased the plasticity index of the clay and compensated for the lime's negative effects [5]. Blended cementitious binder (BBCB) using two types of fly ash 
(66.7\% and $9.0 \%$ of $\mathrm{CaO}$ ) as an alternative for use in soft soil stabilization was tested due to the formation of C-S-H, portlandite and ettringite, as well as secondary calcite [6].

The ageing of clays is a standard process used in ceramic technology for improved plasticity and other technological properties $[7,8]$. Sodium hexametaphosphate affects the ageing of kaolin dispersions [9]. Typical published results of the research about the use of CCFA in the ceramic industry do not solve the question of the influence of fly ash on the rheological properties of plastic dough, which is critical for this type of admixture, especially during the ageing period [10-12]. Class $C$ fly ash is a secondary raw material with a substantial potential in ceramic technology for lightening of brick bodies [13] and as a raw material—a source of $\mathrm{CaO}$ (for example, in the production of ceramic tiles $[14,15]$ ). The influence of class $\mathrm{C}$ fly ash on the rheological properties (setting time) of geopolymers (i.e., in a strongly alkaline environment of $\mathrm{KOH}$ ) was evaluated [16]. The $\mathrm{pH}$ value can strongly affect the plasticity of clays [17]—in the case of kaolinite, liquid limit decreased as $\mathrm{pH}$ increased.

This experimental study aims to answer the question of how class C (fluidized) fly ash affects the ceramic technological properties of the dough (plastic body) based on the mixture of kaolin (a plastic compound of raw materials) and quartz sand. This study presents the plasticity (according to the popular ceramic Pfefferkorn method) in time (ageing process) and the behavior during the drying process (according to Bigot curves).

\section{Materials and Methods}

\subsection{Raw Materials and Test Samples}

Kaolin Zettlitz Ia, micromilled quartz sand and CCFA were used to prepare the raw material mixtures to prepare test samples. Kaolin Zettlitz Ia was originally used in porcelain production. It is still used today as the main plastic component in bodies for plastic molding, slip-casting or isostatic pressing of tableware. It has good plasticity in its raw state and high stability in a fire. The mineralogical composition of used washed kaolin Zettlitz Ia is $91 \%$ of kaolinite, $2 \%$ of quartz and about $7 \%$ of mica minerals. Its chemical composition is presented in Table 1. Chemical composition of kaolin and quartz sand was obtained from technical declaration by supplier and chemical composition of CCFA was obtained by chemical analysis.

Table 1. Chemical composition (wt. \%) of all used materials.

\begin{tabular}{|c|c|c|c|c|c|c|c|c|c|c|c|}
\hline Material & $\mathrm{SiO}_{2}$ & $\mathrm{Al}_{2} \mathrm{O}_{3}$ & $\mathrm{Fe}_{2} \mathrm{O}_{3}$ & $\mathrm{MnO}$ & $\mathrm{TiO}_{2}$ & $\mathrm{CaO}$ & $\mathrm{MgO}$ & $\mathrm{K}_{2} \mathrm{O}$ & $\mathrm{Na}_{2} \mathrm{O}$ & $\mathrm{SO}_{3}$ & LOI \\
\hline Kaolin 1) & 46.80 & 36.60 & 0.90 & 0.00 & 1.70 & 0.70 & 0.50 & \multicolumn{2}{|c|}{1.20} & 0.00 & 13.2 \\
\hline Quartz sand ${ }^{1)}$ & 99.60 & 0.20 & 0.05 & 0.00 & 0.00 & \multicolumn{2}{|c|}{0.10} & \multicolumn{2}{|c|}{0.10} & 0.00 & 0.20 \\
\hline $\mathrm{CCFA}^{2)}$ & 35.00 & 23.30 & 5.50 & 0.10 & 5.40 & 21.50 & 1.60 & 0.50 & 0.10 & 2.50 & 4.50 \\
\hline
\end{tabular}

1) Supplier's declaration, ${ }^{2)}$ own research.

The micromilled sands-silica flour is produced by milling in an ironless environment, by classification using air separators. The raw material used for producing micromilled sands-silica flour is treated silica sand with a $\mathrm{SiO}_{2}$ content above $99 \%$. The chemical purity, favorable particle size distribution, chemical inertia and hardness of micromilled sandssilica flour are appreciated in the production of glass fibers, ceramic enamels, glazes, special mortar mixtures, tile adhesives, molds in the foundry industry and as a filler in plastics.

Fluidized fly ash (class C (ASTM C618)) from Czech thermal power plant (Tisova, CEZ Group, Brezova, Czech Republic) was used for the preparation of laboratory samples. Typical features of all fluidized fly ashes, as seen in the chemical analysis (Table 1), are high in $\mathrm{SO}_{3}$ content $(2.5 \mathrm{wt}$. \% according to chemical composition in the form of anhydrite $\mathrm{CaSO}_{4}$ ) and $\mathrm{CaO}$ (usually up to $15 \%$ - as a calcite $\mathrm{CaCO}_{3}$ and anhydrite) (Figure 1) without the glass phase or mullite, which are typical main mineralogical phases of CFAs. Class $C$ fly ash creates irregularly shaped sharp-edged particles due to lower firing temperatures (Figure 2). 


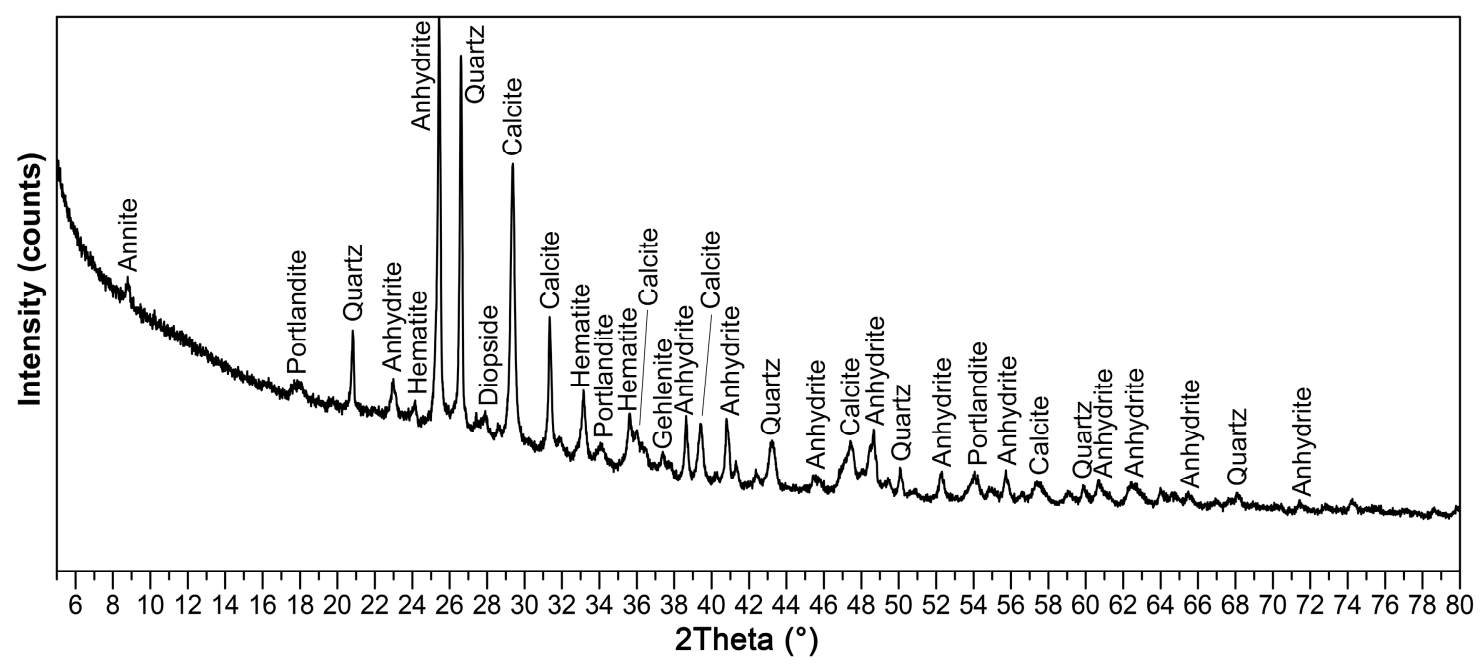

Figure 1. X-ray diffraction pattern of used CCFA.

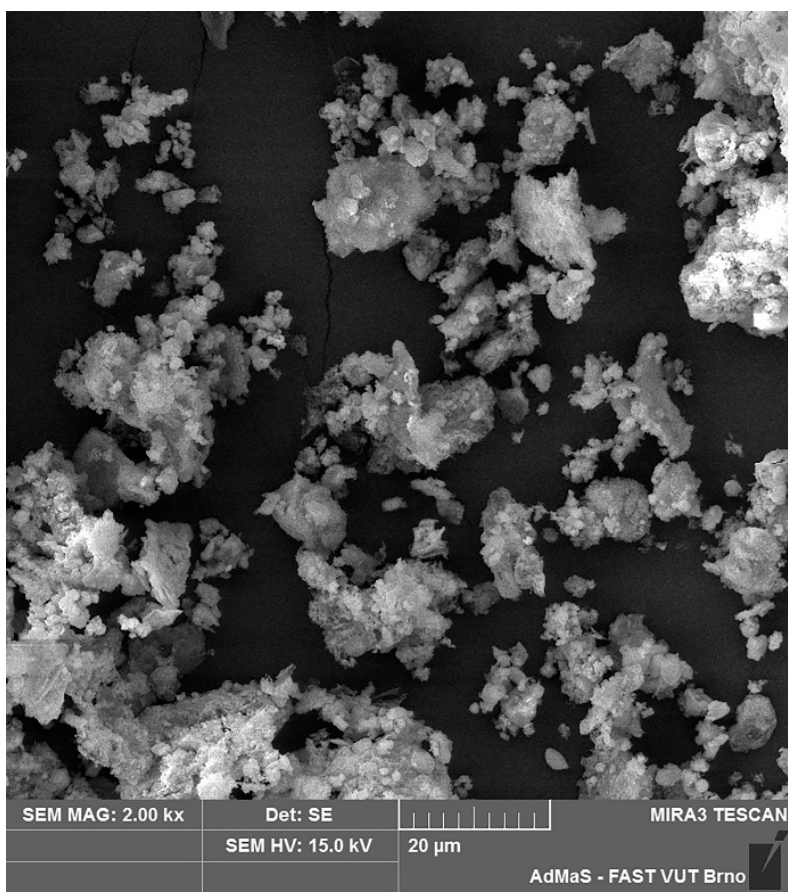

Figure 2. Morphology of used CCFA particles (SEM 2000×).

The granulometry of used materials was determined based on the residue on screens with sizes of $63 \mu \mathrm{m}\left(\mathrm{R}_{63}\right)$ and $43 \mu \mathrm{m}\left(\mathrm{R}_{43}\right)$ and specific surface area according to the Blaine method (EN 196-6) (Table 2). Kaolin and quartz sand are industrially milled commercial products with guaranteed granulometry. The granulometry of fly ash is typical-fly ash is the roughest component of the raw materials mixture, with the highest residue on screens of $63 \mu \mathrm{m}$ and $43 \mu \mathrm{m}$ and the lowest specific surface area.

The test samples were prepared from the mixture by the weight ratio of raw materials$50 \%$ kaolin Zettlitz Ia and 50\% of a non-plastic mixture (micromilled quartz sand-fly ash) (Table 3). 
Table 2. The granulometry of used materials—residue of grains on $63 \mu \mathrm{m}\left(\mathrm{R}_{63}\right)$ and $43 \mu \mathrm{m}\left(\mathrm{R}_{43}\right)$ sieves, specific surface area.

\begin{tabular}{cccc}
\hline Granulometry Parameters & Kaolin & Quartz Sand & Fly Ash \\
\hline $\mathrm{R}_{63}($ wt. $\%)$ & 0.0 & 14.5 & 25.2 \\
$\mathrm{R}_{43}($ wt. $\%)$ & 0.0 & 19.2 & 36.2 \\
Specific surface area $\left(\mathrm{m}^{2} \cdot \mathrm{kg}^{-1}\right)$ & 1750 & 317 & 284 \\
\hline
\end{tabular}

Table 3. The composition and indication of test samples.

\begin{tabular}{cccc}
\hline Sample & Kaolin (wt. \%) & Quartz Sand (wt. \%) & Fly Ash (wt. \%) \\
\hline KQ & 50 & 50 & 0 \\
KQF & 50 & 40 & 10 \\
KQFF & 50 & 30 & 20 \\
\hline
\end{tabular}

\subsection{Methodology}

The raw material mixtures for the production of the test samples were dry mixed for $24 \mathrm{~h}$ in the rotary homogenizer. The plastic body from the homogenized raw materials mixture (Table 3) was prepared by dosing the mixing water in such a quantity that would ensure a deformation ratio, according to the Pfefferkorn test (Czech standard CSN 721074 and [18-20]), of plastic dough to achieve a value of 0.75 (this corresponds to $\mathrm{H}_{\mathrm{f}}=30 \mathrm{~mm}$ ). Measuring plasticity, according to Pfefferkorn [19-21], is based on the principle of impact deformation. A defined cylindrical sample with a diameter of $33 \mathrm{~mm}$ and an initial height of $40 \mathrm{~mm}\left(\mathrm{H}_{0}\right)$ is deformed (final height $\mathrm{H}_{\mathrm{f}}$ ) by a free-falling plate with a mass of $1.192 \mathrm{~kg}$. The deformation heights $\mathrm{H}_{\mathrm{f}}$ for bodies to be extruded lie between $\sim 25 \mathrm{~mm}$ for soft extrusion and $\sim 37 \mathrm{~mm}$ for stiff extrusion [22]. Air drying at about $21^{\circ} \mathrm{C}$ was followed by final drying in the laboratory drier at $110^{\circ} \mathrm{C}$ to achieve constant weight.

The Bigot curve method $[23,24]$ (test samples preparation and measurement method) for DSI-B was used as follows:

1. The dough of the raw material mixtures KQ, KQF and KQFF (Table 4) was made by adding an appropriate amount of initial (mixing) water $\left(\mathrm{W}_{\mathrm{i}}\right)$ determined by the Pfefferkorn test. The test samples were then formed into a rectangular bar of $100 \times 50$ $\times 20 \mathrm{~mm}^{3}$ by hand with the help of a metal form. Some of them were wrapped with a plastic film and kept at room temperature for $24 \mathrm{~h}$ ageing (samples KQ-24, KQF-24, KQFF-24) to describe the Bigot curve of the aged body with higher $\mathrm{H}_{\mathrm{f}}$ (Figures 4, 5 and 6). The dough's ageing refers to the process of the dough maturing with mixing water (to achieve $\mathrm{H}_{\mathrm{f}}=30 \mathrm{~mm}$ ) in a plastic cover without the possibility of drying;

2. The test samples were put on a balance (reproducibility $0.01 \mathrm{~g}$ ) with two cylindrical supports. The changes in the length $(100 \mathrm{~mm})$ were continually observed using a contactless Micro-Epsilon OptoNCDT 1420 laser triangulation sensor (Bechyne, Czech Republic) (reproducibility $0.5 \mu \mathrm{m}$ ). The specimen was kept in a room protected from airflow for $24 \mathrm{~h}$;

3. The specimen was dried at $110{ }^{\circ} \mathrm{C}$ until the weight became constant, and the length of the dried specimen was measured to calculate the drying shrinkage (DS). The graph of the relationship between shrinkage and water content was plotted (Bigot curve). The Drying Sensitivity Index-Bigot DSI-B was calculated using the following equation:

$$
\text { DSI-B }=\left[\left(W_{i}-W_{c}\right) \cdot D S\right] / 100
$$

where:

$\mathrm{W}_{\mathrm{i}}$ is the initial water content of the dough during test samples' preparation (\%); $\mathrm{W}_{\mathrm{c}}$ is the critical water content of test samples subtracted from the Bigot curve (Figure 3) (\%);

DS is drying shrinkage after drying at $110{ }^{\circ} \mathrm{C}(\%)$. 
X-ray diffraction analysis (XRD; Panalytical Empyrean, PANalytical B.V., Almelo, Netherlands) with $\mathrm{CuK} \alpha$ as a radiation source, an accelerating voltage of $45 \mathrm{kV}$, beam current 40 $\mathrm{mA}$, diffraction angle $2 \theta$ in the range from $5^{\circ}$ to $80^{\circ}$ with a step scan of $0.01^{\circ}$ and scanning electron microscopy (SEM; Tescan Mira3, Tescan Orsay Holding a.s., Brno, Czech Republic) were used to determine mineralogical composition and morphology of the crystal structure.

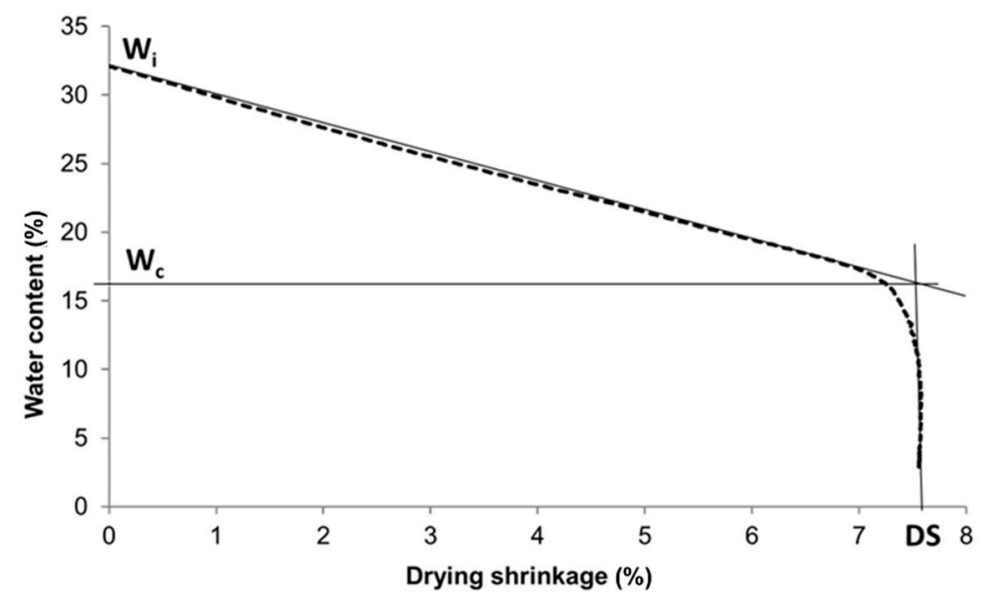

Figure 3. Graphical determination of the initial water content $W_{i}$ and critical water content $W_{c}$ from the Bigot curve.

Table 4. Properties of dried green samples.

\begin{tabular}{cccc}
\hline Sample & $\mathbf{W}_{\mathbf{i}} \mathbf{1}^{\mathbf{1}}$ (wt. \%) & $\begin{array}{c}\text { Bulk Density of Green } \\
\text { Body (wt. \%) }\end{array}$ & $\begin{array}{c}\text { Bulk Density of Green Body } \\
\text { Aged for 24 } \mathbf{h} \text { (wt. \%) }\end{array}$ \\
\hline $\mathrm{KQ}(-24)$ & 25.8 & 1730 & 1730 \\
$\mathrm{KQF}(-24)$ & 32.0 & 1565 & 1530 \\
$\mathrm{KQFF}(-24)$ & 34.1 & 1470 & 1390 \\
\hline
\end{tabular}

${ }^{1} \mathrm{~W}_{\mathrm{i}}$ is the initial (mixing) water to achieve $\mathrm{H}_{\mathrm{f}}=30 \mathrm{~mm}$, according to the Pfefferkorn test.

\section{Results and Discussion}

Class $C$ fly ash increases the initial (mixing) water content. The higher water content was needed to achieve the dough with the same plasticity (it was chosen as $\mathrm{H}_{\mathrm{f}}=30 \mathrm{~mm}$, according to the Pfefferkorn test).

The need for a higher content of mixing water resulted in a lower bulk density of dried green bodies. This decrease in the bulk density is mere evidence for samples that were aged in a plastic wrap for $24 \mathrm{~h}$ after the preparation of test samples from dough with initial water $\mathrm{W}_{\mathrm{i}}$, according to Table 4 .

The plastic dough ageing process is documented in Figure 4-when CCFA is not used, the plasticity (final height $\mathrm{H}_{\mathrm{f}}$ ) of the dough is approximately constant in time (KQ curve). Increasing the CCFA content (KQF-KQFF) increases the height of the deformed Pfefferkorn's conical test sample $\mathrm{H}_{\mathrm{f}}$ in time (i.e., the dough solidifies) in Figures 5 and 6.

While ageing the dough, the CCFA content (KQF, KQFF) solidifies- the final height $\mathrm{H}_{\mathrm{f}}$ of the deformed cones after the Pfefferkorn test (Figure 4) increases in time, with an increasing volume of CCFA in the raw materials mixture. There is evidence that the KQ mixture without CCFA shows relative constant plasticity during the ageing, and the admixture of CCFA increases Hf very intensively, especially in the first $10 \mathrm{~h}$ of ageing. The KQFF mixture with the highest fly ash content $(20 \mathrm{wt}$. \%) lost its plasticity after $30 \mathrm{~h}$ of measuring (Figure 4 shows the end of the measuring process-the value $\mathrm{H}_{\mathrm{f}}=36 \mathrm{~mm}$ can no longer be considered a plastic state). 


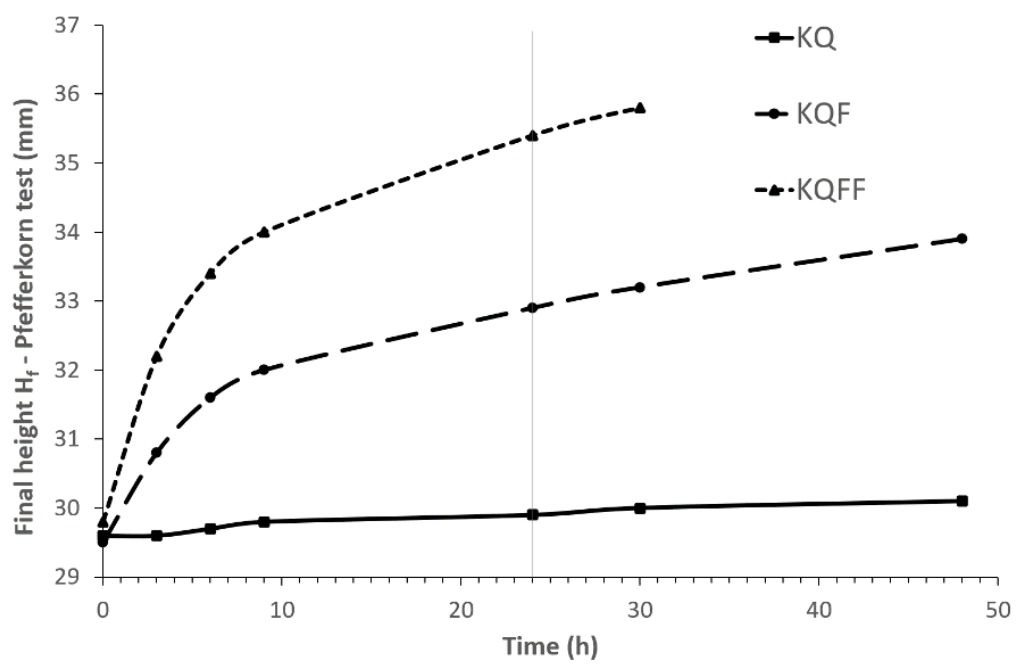

Figure 4. The effect of plastic body ageing on plasticity, according to the Pfefferkorn test-deformed final height $\mathrm{H}_{\mathrm{f}}$.

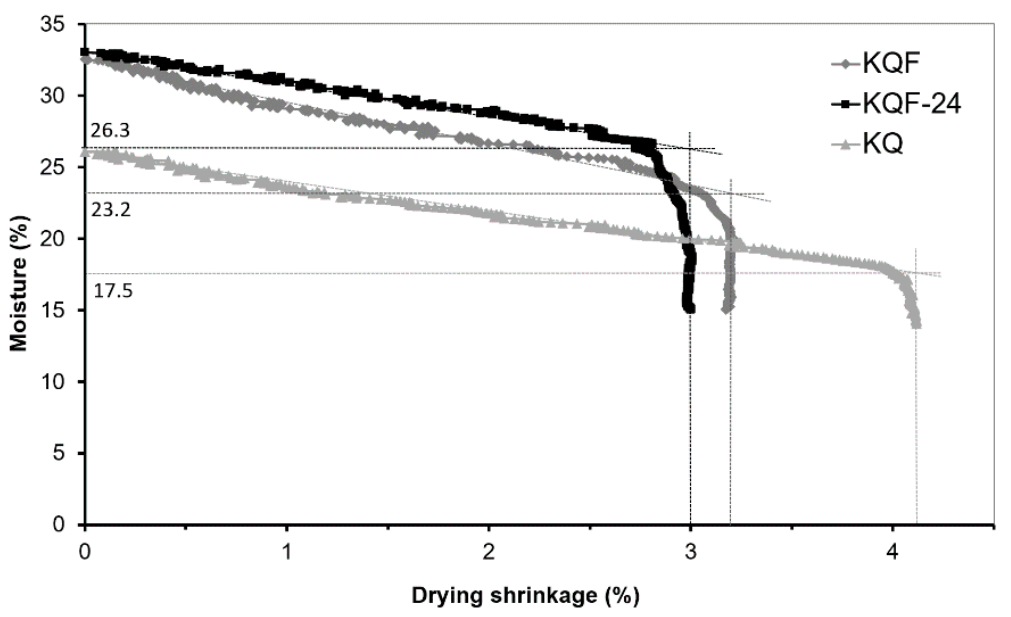

Figure 5. Bigot curves of KQF samples measured on fresh (KQF) and $24 \mathrm{~h}$ aged (KQF-24) test samples compared with a sample without CCFA (KQ).

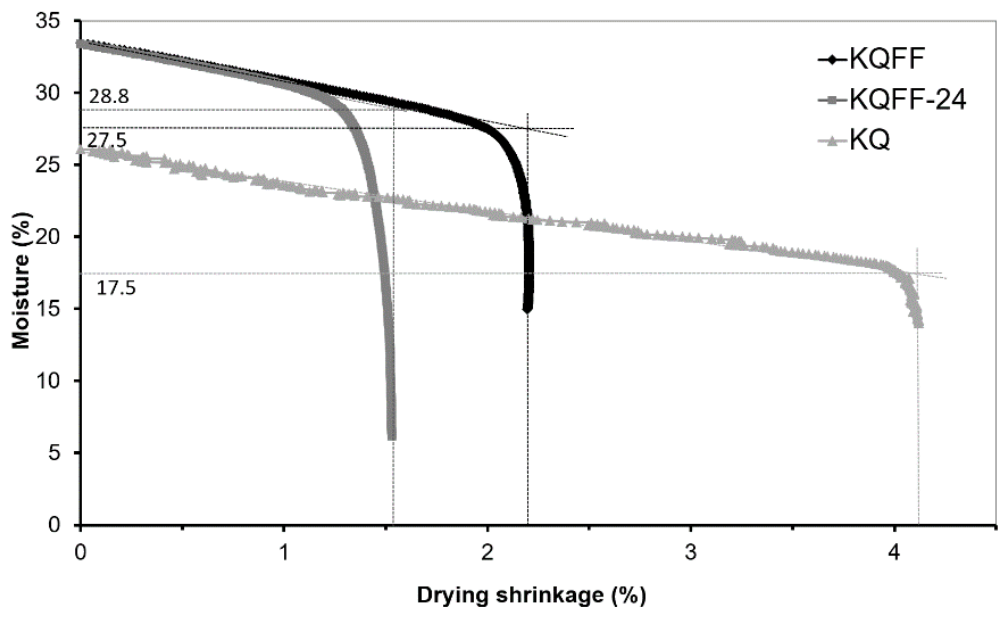

Figure 6. Bigot curves of KQFF samples measured on fresh (KQFF) and 24 h aged (KQFF-24) test samples compared with a sample without CCFA (KQ).

A more pronounced effect of solidifying the prepared ceramic dough during the ageing can be observed in the Bigot curve if $20 \%$ fly ash (KQFF) is used, as critical water 
content $W_{i}$ is reached much earlier, and DS is reduced. Both of these effects are even more intense after the dough has aged for $24 \mathrm{~h}$. Thus, the DSI-B value decreases with increasing fly ash content, as does the dough's ageing.

An increase in the initial water content $\mathrm{W}_{\mathrm{i}}$ and a decrease in the DS significantly reduces the bulk density of the green and dried green body. Therefore, CCFA can be considered to be a significant non-combustible light-weighting agent, which is confirmed by research in the field of class $C$ fly ash using in brick clays [13].

Class $C$ fly ash creates a bond in the green body, possibly mediated by the binders' anhydrite and calcium oxide, which finally manifests itself by increasing the MOR of the dried green body with the highest fly ash content (KQFF) compared with the dried green body without CCFA content (KQ) (Table 5).

Table 5. Drying Sensitivity Index, according to Bigot (DSI-B), and Modulus of Rupture (MOR) of dried test samples depending on the fly ash content and $24 \mathrm{~h}$ ageing (KQ-24, KQF-24, KQFF-24).

\begin{tabular}{ccccccc}
\hline Mixture & KQ & KQ-24 & KQF & KQF-24 & KQFF & KQFF-24 \\
\hline $\begin{array}{c}\text { DSI-B (-) } \\
\text { MOR }\end{array}$ & 0.34 & 0.34 & 0.28 & 0.17 & 0.14 & 0.08 \\
(MPa) & 0.72 & 0.75 & 0.66 & 0.58 & 1.48 & 1.02 \\
\hline
\end{tabular}

However, the presumed formation of a hydraulic bond via calcium-silicate-hydrate (C-S-H gel) and ettringite [6] was not confirmed by an X-ray diffraction analysis (Figure 7). However, authors [6] used high-calcium fly ash with a much higher $\mathrm{CaO}$ content (66.76 wt. \%), which corresponds to the composition of Portland cement [25]. Only phases present in individual input raw materials (kaolin, quartz sand and CCFA) were discovered in the KQFF dried green body. Hydration of anhydrite in KQF and KQFF bodies is expected [26]. Figure 8 represents the difference in porosity and microstructure of dried green bodies depending on the amount of CCFA addition (0, 10 and $20 \mathrm{wt}$. \%).

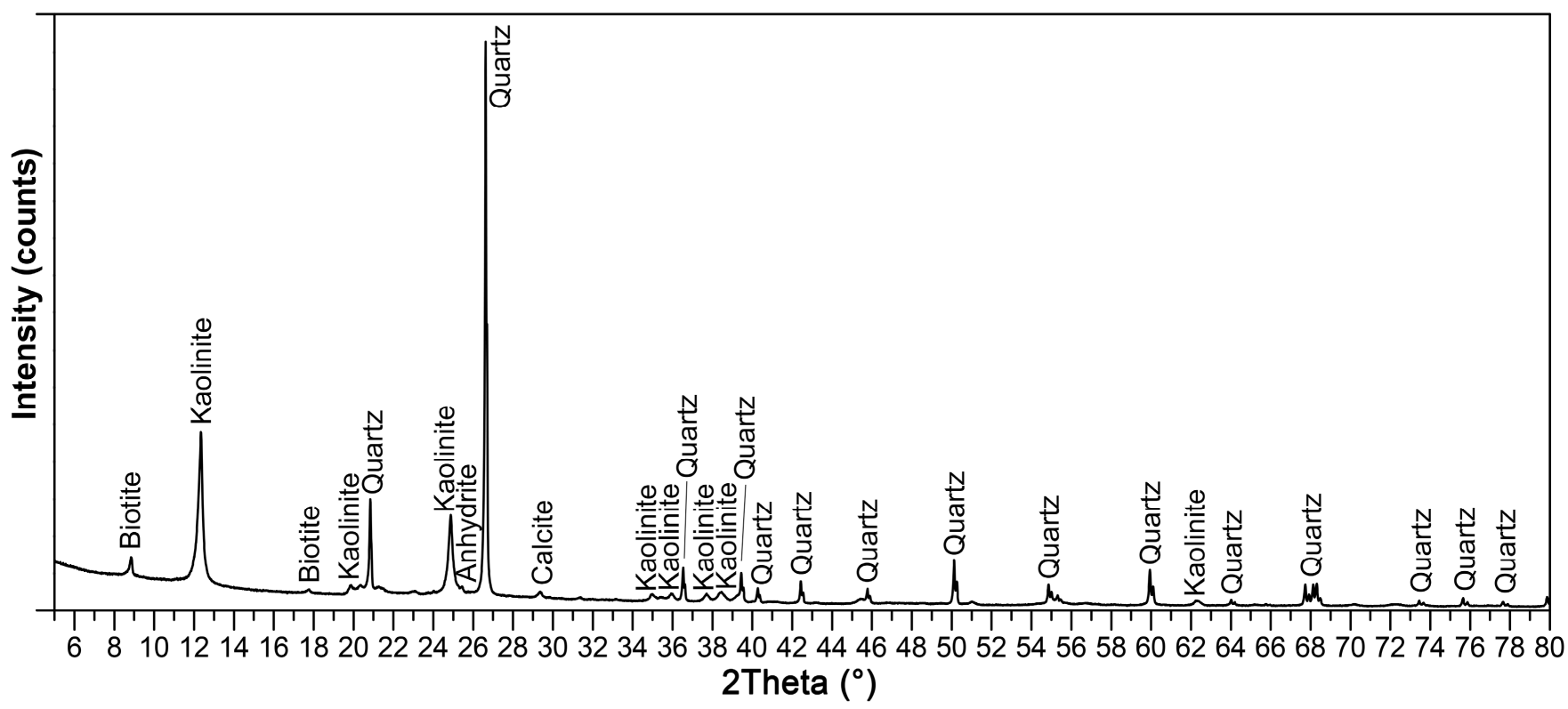

Figure 7. X-ray diffraction pattern of dried KQF green body. 


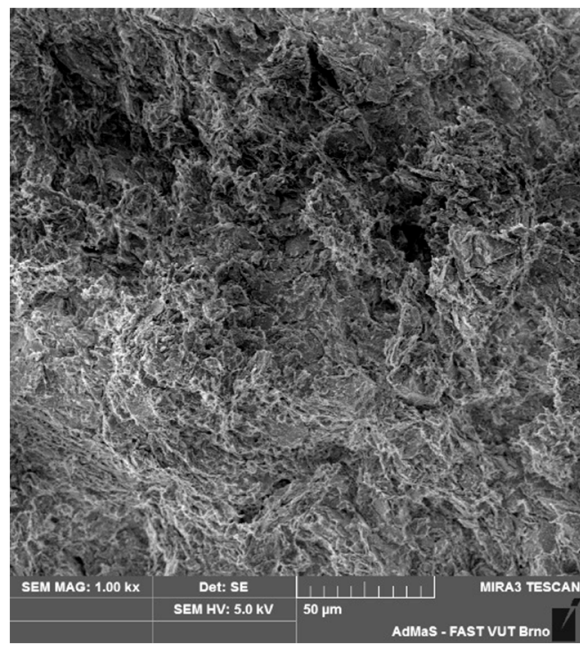

(a)

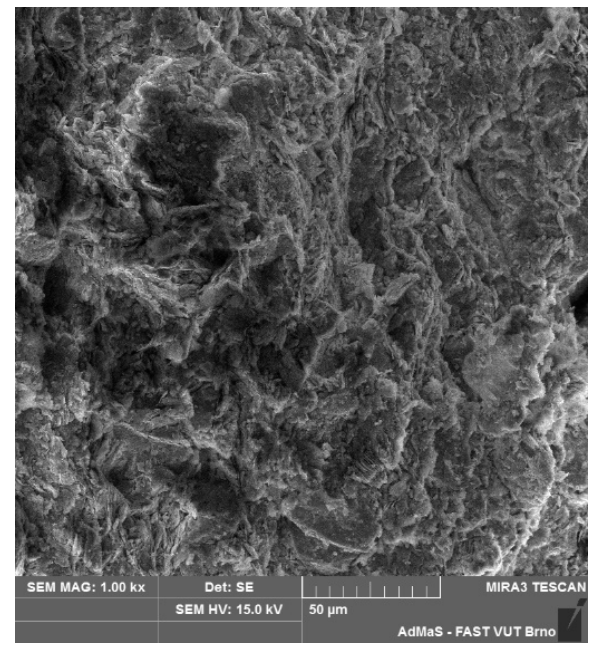

(b)

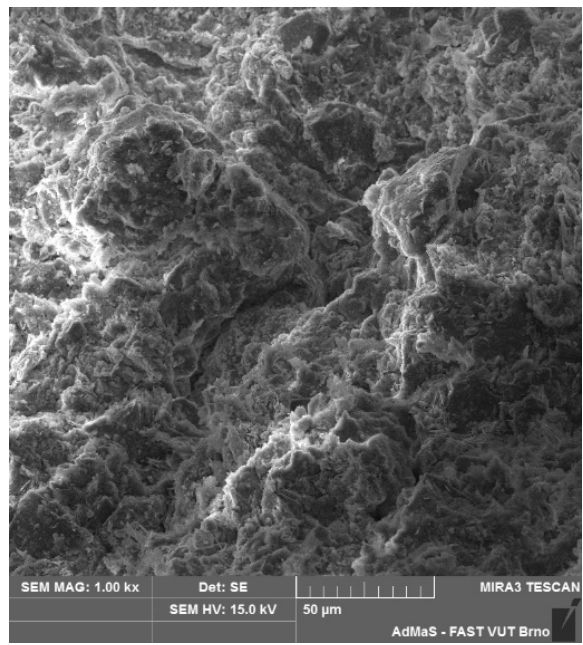

(c)

Figure 8. SEM of dried green bodies (a) mixture KQ; (b) mixture KQF; (c) mixture KQFF; magnification 1000×.

\section{Conclusions}

Class C fly ash is a secondary raw material generated in large volumes with substantial potential in ceramic technology. It was used in research for lightening of brick bodies and also as a raw material, an inexpensive source of $\mathrm{CaO}$, in the production of ceramic tiles. However, it is necessary to take into account the solidification of the plastic dough, which is a property of this type of fly ash, during the ageing process, even without the access to airflow. Class $\mathrm{C}$ fly ash in admixture with quartz sand and kaolin increases the initial (mixing) water for the preparation of ceramic dough with constant plasticity (the same height of the deformed cone $\mathrm{H}_{\mathrm{f}}$, according to the Pfefferkorn test), and $\mathrm{H}_{\mathrm{f}}$ increases during the plastic dough's ageing. This effect is documented on Bigot curves-higher fly ash content decreases the DS of the plastic dough, especially while drying samples that have been aged for $24 \mathrm{~h}$ in the plastic wrap (without the possibility of drying). Plastic dough's ageing increases the porosity of the dried green body with increasing CCFA content in the raw materials mixture and increasing ageing time.

Author Contributions: Conceptualization, R.S. and M.N.; methodology, R.S.; software, R.S.; validation, R.S. and M.N.; formal analysis, R.S.; investigation, R.S.; resources, R.S.; data curation, M.N.; writing—original draft preparation, R.S.; writing—review and editing, M.N.; visualization, R.S. and M.N.; supervision, R.S.; project administration, R.S.; funding acquisition, R.S. All authors have read and agreed to the published version of the manuscript.

Funding: This research was funded by Czech Science Foundation (GAČR), grant number 18-02815S with project name Elimination of Sulphur oxide emission during the firing of ceramic bodies based on fly ashes of class $C$.

Data Availability Statement: The data presented in this study are available upon request from the corresponding author.

Conflicts of Interest: The authors declare no conflict of interest.

\section{References}

1. Mollamahmutoglu, M.; Yilmaz, Y.; Güngör, G.A. Effect of a Class C Fly Ash on the Geotechnical Properties of an Expansive Soil. Int. J. Eng. Res. Dev. 2009, 1, 1-6.

2. Hayder, H.A. Effect of Fly Ash on Geotechnical Properties of Expansive soil. J. Eng. Dev. 2012, 16, $306-316$.

3. Yin, C.; Zhang, W.; Jiang, X.; Huang, Z. Effects of Initial Water Content on Microstructure and Mechanical Properties of Lean Clay Soil Stabilized by Compound Calcium-Based Stabilizer. Materials 2018, 11, 1933. [CrossRef] [PubMed]

4. Mir, B.A. Some studies on the effect of fly ash and lime on physical and mechanical properties of expansive clay. Int. J. Civ. Eng. 2015, 13, 1-12. 
5. Cheshomi, A.; Eshaghi, A.; Hassanpour, J. Effect of lime and fly ash on swelling percentage and Atterberg limits of sulfate-bearing clay. Appl. Clay Sci. 2017, 135, 190-198. [CrossRef]

6. Jafera, H.; Atherton, W.; Sadique, M.; Ruddock, F.; Loffill, E. Stabilisation of soft soil using binary blending of high calcium fly ash and palm oil fuel ash. Appl. Clay Sci. 2018, 152, 323-332. [CrossRef]

7. Gaidzinski, R.; Duailibi, J.; Tavares, L.M. Influence of aging on the technological properties of clays in the ceramic industry. Appl. Clay Sci. 2011, 54, 47-52. [CrossRef]

8. Shahriar, A.R.; Jadid, R. An experimental investigation on the effect of thixotropic aging on primary and secondary compression of reconstituted dredged clays. Appl. Clay Sci. 2018, 162, 524-533. [CrossRef]

9. Andreola, F.; Castellini, E.; Ferreira, J.M.F.; Olhero, S.; Romagnoli, M. Effect of sodium hexametaphosphate and ageing on the rheological behaviour of kaolin dispersions. Appl. Clay Sci. 2006, 31, 56-64. [CrossRef]

10. Queralt, I.; Querol, X.; López-Soler, A.; Plana, F. Use of coal fly ash for ceramics: A case study for a large Spanish power station. Fuel 1997, 76, 787-791. [CrossRef]

11. Little, M.R.; Adell, V.; Boccaccini, A.R.; Cheeseman, C.R. Production of novel ceramic materials from coal fly ash and metal finishing wastes. Resour. Conserv. Recycl. 2008, 52, 1329-1335. [CrossRef]

12. Abbas, S.; Saleem, M.A.; Kazmi, S.M.S.; Munir, M.J. Production of sustainable clay bricks using waste fly ash: Mechanical and durability properties. J. Build. Eng. 2017, 14, 7-14. [CrossRef]

13. Sokolar, R.; Nguyen, M. Influence of Class C Fly Ash on the Properties of Plastic Clay and Fired Brick Body. Mater. Tehnol. 2020, 54, 107-111. [CrossRef]

14. Biffi, G. Book for the Production of Ceramic Tiles, 1st ed.; Gruppo Editionale: Faenza, Italy, 2003.

15. Zimmer, A.; Bergmann, C.P. Fly ash of mineral coal as ceramic tiles raw material. Waste Manag. 2007, 27, 59-68. [CrossRef] [PubMed]

16. Hemra, K.; Yamaguchi, S.; Kobayashi, T.; Aungkavattana, P.; Jiemsirilers, S. Compressive Strength and Setting Time Modification of Class C Fly Ash-Based Geopolymer Partially Replaced with Kaolin and Metakaolin. Key Eng. Mat. 2018, 766, 157-163. [CrossRef]

17. Nivedya, K. Study on the Effect of $\mathrm{pH}$ on the Atterberg Limits of Kaolinitic and Montmorillonitic Clay. Geotech. Characterisation Geoenvironmental Engl. 2018, 1, 251-256.

18. Modesto, C.O.; Bernardin, A.M. Determination of clay plasticity: Indentation method versus Pfefferkorn method. Appl. Clay Sci. 2008, 40, 15-19. [CrossRef]

19. Pfefferkorn, K. Ein Beitrag zur Bestimmung der Plastizität in Tonen und Kaolinen. Sprechsaal 1924, 57, $297-299$.

20. Grim, R.E. Clay Mineralogy, 2nd ed.; Mc-Graw Hill: New York, NY, USA, 1968; p. 596.

21. Ryan, W.; Radford, C. Whitewares Production, Testing and Quality Control, 1st ed.; Pergamon Press: New York, NY, USA, 1987; p. 333.

22. Händle, F. Rheology and Extrudability of Ceramic Compounds. In Extrusion in Ceramics, 1st ed.; Derby., B., Ed.; Springer: New York, NY, USA, 2007; pp. 175-188.

23. Bigot, A. Retrait au Sechage des Kaolins et Argiles. Rep. Acad. Sci. 1921, 755-758.

24. Aungatichart, P.; Wada, S. Correlation between Bigot and Ratzenberger drying sensitivity indices of red clay from Ratchaburi province (Thailand). Appl. Clay Sci. 2009, 42, 182-185. [CrossRef]

25. Ho, L.S.; Nakarai, K.; Eguchi, K.; Ogawa, Y. Difference in Strength Development between Cement-treated Sand and Mortar with Various Cement Types and Curing Temperatures. Materials 2020, 13, 4999. [CrossRef] [PubMed]

26. Liu, W.; Hou, H.; Zhang, C. Feasibility study on solidification of municipal solid waste incinerator fly ash with circulating fluidized bed combustion coal fly ash. WMER 2009, 27, 258-266. 